\title{
Romatoid Artritli Kadın Hastalarda Skapular Diskinezinin Hastalık Aktivitesi, Yaşam Kalitesi ve Engel Seviyesine Etkisi
}

Effect of Scapular Dyskinesis on Disease Activity, Quality of Life, Level of Disability in Female Patients with Rheumatoid Arthritis

\author{
Mehmet DELEN ${ }^{1}$, Deran OSKAY ${ }^{2}$, Songül BAĞLAN ${ }^{3}$, Zeynep TUNA ${ }^{4}$, Oğuzhan METE ${ }^{5}$, \\ Ahmet GÖKKURT', Gizem TÖRE ${ }^{3}$, Abdurrahman TUFAN ${ }^{6}$ \\ ${ }_{1}^{1}$ Uzm. Fzt., Gazi Üniversitesi Sağlık Bilimleri Enstitüsü Fizyoterapi Ve Rehabilitasyon Anabilim Dalı, Ankara. \\ ${ }^{2}$ Doç. Dr., Gazi Üniversitesi Sağlık Bilimleri Enstitüsü Fizyoterapi Ve Rehabilitasyon Anabilim Dalı, Ankara. \\ ${ }^{3}$ Arş. Gör., Gazi Üniversitesi Sağlık Bilimleri Enstitüsü Fizyoterapi Ve Rehabilitasyon Anabilim Dalı, Ankara. \\ ${ }^{4}$ Dr. Fzt., Gazi Üniversitesi Sağlık Bilimleri Enstitüsü Fizyoterapi Ve Rehabilitasyon Anabilim Dalı, Ankara. \\ ${ }^{5}$ Arş. Gör., Yıldırım Beyazıt Üniversitesi Fizyoterapi Ve Rehabilitasyon Anabilim Dalı, Ankara. \\ ${ }^{6}$ Doç. Dr., Gazi Üniversitesi Tıp Fakültesi Romatoloji Bölümü, Ankara.
}

\section{ÖZ}

\begin{abstract}
Amaç: Bu çalışmanın amacı romatoid artrit (RA) tanısı olan kadın hastalarda skapular diskinezinin (SD) hastalık aktivitesi, yaşam kalitesi ve engel seviyesi üzerine etkisini araştırmaktır. Gereç ve Yöntem: Çalışmaya RA tanısı konmuş 52 kadın hasta dâhil edildi. Hastalar SD olan (Grup 1) ve olmayan (Grup 2) şeklinde 26'şar kişilik iki gruba ayrıldı. Hastaların hastalık aktivitesi Romatoid Artrit Hastalık Aktivitesi Endeksi-5 (T-RADAl-5) anketi, engel seviyesi Kol, Omuz ve El Engel Anketi (DASH-T), ağrı düzeyi Görsel Analog Skalası (VAS), omuz çevresi kas kuvveti manuel kas kuvveti testi, SD’leri gözlemsel skapular diskinezi değerlendirmesi ve Lateral skapular kaydırma testi (LSKT), yaşam kaliteleri Romatoid Artrit Yaşam Kalitesi Anketi (RAQoL-T) ile değerlendirildi. Tüm anketlerin Türkçe versiyonları kullanıldı. Sonuçlar: İki grup da demografik açıdan birbirine benzer bulundu. SD'si olan RA'lı hastaların DASH $(p=0,001)$, RADAl-5 $(p<0,001)$, RAQoL $(p<0,001)$, VAS sağ $(p=0,002)$ ve sol $(p=0,001)$ skorları ile diğer grubun skorları arasında istatistiksel olarak Grup 2 lehine anlamlı fark bulundu. Grup 1 hastalarının SD'li taraf omuz eksternal rotasyon kas kuvveti, diğer omzun eksternal rotasyon kas kuvvetinden istatistiksel olarak anlamlı derecede düşük bulundu $(p=0,046)$. Tartışma: SD'si olan RA hastalarında klinik bulguları SD'si olmayan gruba göre daha kötüdür. Bu nedenle SD bulgusu bu hastalarda klinik bulgulardaki kayıpların göstergesi olabilir. Klinisyenler tarafından SD gözardı edilmemelidir.
\end{abstract}

Anahtar Kelimeler: Romatoid Artrit; Skapular Diskinezi; Yaşam Kalitesi; Engel Seviyesi; Hastalık Aktivitesi

\section{ABSTRACT}

Purpose: The purpose of the study was to investigate the effects of scapular dyskinesis on quality of life and level of disability among female patients with RA. Material and Methods: 52 patients with RA were evaluated for the study, and they were divided equally into two groups with the following criteria: patient has scapular dyskinesis (SD) (Group 1) or patient does not have SD (Group 2). Disability level, Quality of Life (QoL), disease activity, scapular dyskinesis, pain level and muscle strength were assessed with Turkish version of Disabilities of Arm, Shoulder and Hand questionnaire (DASH-T), Rheumatoid Arthritis specific Quality of Life questionnaire (RAQoL-T), Rheumatoid Arthritis Disease Activity Index-5 (T-RADAI5), Lateral Scapular Slide Test, Visual Analog Scale (VAS), manual muscle test respectively. Results: Both groups were similar demographically. Results of the patient with SD (Group 1) were significantly different in a negative way than those of the patient without SD (Group 1) in DASH ( $p=0,001)$, RADAI-5 $(p<0,001)$, RAQoL $(p<0,001)$, VAS right shoulder $(p=0,002)$ and left shoulder $(p=0,001)$. In Group 1 , asymmetric side shoulder had less external rotation muscle strength compared to simetric side shoulder $(p=0,046)$. Discussion: Clinic outcomes of RA patients with SD are worse than those of without SD. Hence, SD may be linked to demonstration of loss of clinic outcomes. Clinicians should not ignore SD in patients with RA.

Key Words: Rheumatoid Artritis; Scapular Dyskinesis; Quality of Life; Level of Disability; Disease Activity

Sorumlu Yazar (Corresponding Author): Mehmet DELEN e-mail: delenmehmet@yahoo.com

ORCID ID: 0000-0002-0693-8046

Geliş Tarihi (Received): 12.09.2017; Kabul Tarihi (Accepted): 16.05.2018 
Romatoid artrit (RA) kronik, nedeni bilinmeyen otoimmün ve eklemin sinoviyal dokusunun inflamasyonu ile karakterize bir hastalıktır. RA, dünya genelinde popülasyonun yaklaşık olarak $\% 1$ 'ini etkilemektedir. RA'da genelikle etkilenen eklemler el-el bileği, ayak-ayak bileği olmakla birlikte diğer eklemler de etkilenebilmektedir (O'Dell, Imboden ve Miller, 2013; Tamowska, Amernik, Matyia ve ark, 2004; Helmick, Felson, Lawrence ve ark, 2008). Büyük eklemlerin tutulumu ise daha geç dönemlerde görülmektedir (O'Dell ve ark, 2013). RA'da görülen sinovyal inflamasyon omuz yaralanmalarında ek risk oluşturmaktadır (Stegbauer, Rump, Weiner ve ark, 2008).

Omuz bölgesi, kas iskelet sistemi ile ilgili ağrının en sık görüldüğü üçüncü bölgedir (Urwin, Symmons, Allison ve ark, 1998). RA'da görülen sinovyal inflamasyon; diğer patolojilerden farklı olarak, omuz yaralanmalarında ek risk oluşturmaktadır. Sinovitler, bursitler ve tendinitler RA'lı hastaların kas kuvvetinde azalmaya, kalıcı ağrıya, normal eklem hareketinde azalmaya ve eklem hasarı hastaların fonksiyonlarının azalmasına ve günlük aktivitelerde zorluk yaşamalarına neden olabilmektedir. RA'ı hastalarda aktivite limitasyonları ile omuz fonksiyonları ilişkilidir (Boström, Harms-Ringdahl, Nordemar ve ark, 1995; Slungaard ve Mengshoel, 2013; Bilberg, Bremell ve Mannerkorpi, 2012; Böstrom, 2000).

Skapula hareketlerinin normal omuz kinematiğine önemli katkıları vardır. Bu nedenle omuz ile ilgili şikâyeti olan hastaların hareket değerlendirmesi yapılırken, skapulanın gözardı edilmemesi önerilir. Düzenli skapular değerlendirme, omuz ağıı semptomlarının tedavi edilebilmesi için hayati olabilir (Warth ve Millett, 2015; McKay, 2015). Skapulanın fonksiyonlarından ilki, deltoid ve rotator manşet kasları ile glenohumeral eklemdeki hareketlere stabil bir destek yüzeyi oluşturmaktır. İkicisi, oluşturduğu doğru pozisyon ile koordineli kas kontraksiyonunun sağlanmasıdır. Bu da karşılıklı kuvvet çiftlerinin koordinasyonu korumasıyla oluşan glenohumeral eklemsel uyumluluğunu fasilite eder. Üçüncüsü ise, üst ekstremitede oluşan kuvvetlerin kinetik zincire aktarılmasıdır. Bu nedenle skapulanın doğru kinematiği üst ekstremitenin fonksiyonları için önemlidir (Warth ve ark, 2015).

Skapular diskinezi; skapulanın pozisyonunun ve hareketinin değişmesi olarak tanımlanır (Kibler, Ludewig, McClure ve ark, 2013). Glenohumeral instabilite, rotator manşet problemleri ve labral yırtık gibi omuz problemleri olan hastalarda skapular diskinezi \%68-100 arasında rapor edilmiştir
(Burkhart, Morgan ve Kibler, 2000; Paletta, Warner, Warren ve ark, 1997; Warner, Micheli, Arslanian ve ark, 1992).

Omuz problemlerinin yaşandığı RA'da, omuzskapula arasındaki ilişkiden dolayı omuz problemlerinin temel nedeni skapular problemler olabilir. Bu nedenle RA'lı hastalarda skapular diskinezinin hastalık aktivitesi, yaşam kalitesi, hastalık aktivitesi ve engel düzeyi arasındaki ilişkinin araştırıması ve bilinmesi bu hastalığın tedavi programına yön vermesi açısından önemlidir. Çalışmamızın amacı diskinezinin yaşam kalitesi ve engel seviyesi üzerine etkisini incelemektir.

\section{GEREÇ VE YÖNTEM}

Bu çalışma Nisan 2016 ile Eylül 2016 tarihleri arasında Gazi Üniversitesi Sağlık Bilimleri Fakültesi Fizyoterapi ve Rehabilitasyon bölümünde gerçekleştirildi. Hastaların tüm değerlendirmeleri aynı fizyoterapist tarafından yapıldı. Çalışmaya dâhil edilme kriterleri; a) kesinleşmiş RA tanısı alması, b) 25-65 yaş aralığında olması, c) aktif omuz abduksiyonunun minimum $90^{\circ}$ olması, d) el deformitesi olmaması, e) omuz çevresi kasların manuel kas kuvvetinin 3 ve üstü olması idi. Dışlama kriteri; 1) erkek olma, 2) RA tanısının kesinleşmemesi, 3) değerlendirmelerde kooperasyon eksikliği, 4) manuel kas kuvveti sonucunun 0-2 olma, 5) el deformitesi varlığı idi. Çalışmaya dâhil edilecek hasta sayısı POWER analiz sonucuna göre belirlendi.

Uzman bir romatoloji doktoru tarafindan 2010 Amerikan Romatoloji Derneği (ACR)/Avrupa Romatizma Birliği (EULAR) kriterlerine (Krabben, Huizinga ve van der Helm-van Mil, 2012) göre RA tanıları konulan 52 hasta, lateral skapular kaydırma testi ve gözlemsel skapular diskenzi testlerinin sonuçlarına göre skapular diskinezisi olan ve olmayan şeklinde 26'şar kişilik iki gruba ayrıldı. Çalışmaya dâhil edilen her hasta bilgilendirilerek yazılı onayları alındı. Araştırma Gazi Üniversitesi Klinik Araştırmalar Etik Kurulu tarafından değerlendirilerek onaylandı (11.04.2016 tarihli ve 198 sayılı karar).

\section{Kas Kuvveti Değerlendirmesi}

Hastaların omuz fleksiyon, abdüksiyon, internal rotasyon, eksternal rotasyon, supraspinatus ve biseps kasları kas kuvveti manuel kas testi ile değerlendirildi. Manuel kas testi puanlamasında Tıbbi Araştrımalar Derneği (Medical Research Council) (MRC) tarafından geliştirilen 0-5 arası skala kullanıldı. Bu skalada: 0: Kas kontraksiyonu yok, 1: Titreme veya kasılma belirtisi, 2: Yer çekimi elimine 
edildiğinde ortamda aktif hareket, 3: Yer çekimine karşı aktif hareket, 4: Yer çekimine ve dirence karşı aktif hareket, 5: Normal güç göstermektedir (Leeb, Haindl, Maktari ve ark, 2008).

\section{Skapular Diskinezinin Değerlendirilmesi}

Gözlemsel Skapular Diskinezi Değerlendirmesi'nde, hastalardan 3-5 kez arka arkaya tekrarlı bir şekilde, sagital düzlemde bilateral omuz elevasyonu hareketini yapması istendi. Hareket boyunca skapulaların medial kenarı gözlemlendi. Skapulanın medial kenarında inferomedial kenar, tüm medial kenar veya superior skapular kenar belirginleşmesi gözlemlenirse skapular diskinezi var şeklinde not edildi. Bunlardan hiçbiri gözlemlenmediğinde skapular diskinezi yok şeklinde not edildi (Uhl, Kibler, Gecewich ve ark, 2009).

Lateral skapular kaydırma testi (LSKT)'nde bireyler ayaktayken, 3 farklı kol pozisyonda değerlendirmeleri yapıldı. Bu pozisyonlar; a)kolların vücudunun yanında olduğu, b)ellerin kalça üstünde olduğu, c)kolların $90^{\circ}$ abdüksiyonda olduğu pozisyonlardır. Bu üç pozisyonda skapula alt açısı ile aynı seviyede olan vertebranın spinous çıkıntınsı ile hastanın skapulasının alt açısı arasındaki uzaklık bilateral mezuro ile ölçüldü. Aynı pozisyondaki ölçümler arası fark 1,5 santimetre $(\mathrm{cm})$ 'den fazla ise skapular diskinezi var olarak kaydedildi (Kibler 1998).

Hem gözlemsel hem de LSKT değerlendirmesi pozitif olan hastalar skapular diskinesi var olarak kaydedildi.

\section{Yaşam Kalitesinin Değerlendirilmesi}

Yaşam kalitesinin değerlendirilmesinde Romatoid Artrit Yaşam Kalitesi Anketi Türkçe versiyonu (RAQoL-T) kullanıldı. Bu anket RA'ya özel olarak geliştirilmiş yaşam kalitesi anketidir. Hastalık aktivite düzeyine, hastalığın şiddetine ve zaman içerisinde gerçekleşen değişikliklere duyarlıdır. Evet/hayır şeklindeki 30 soruluk anketi hastalar kendileri cevapladı. Birey anketten maksimum 30 puan, minimum da 0 puan alabilir. Yüksek puan alan hastaların yaşam kaliteleri düşük düzeyde olarak yorumlandı (Kutlay, Küçükdeveci, Gönül ve ark. 2003).

\section{Ağrı Seviyesinin Değerlendirilmesi}

Ağrı seviyesi Görsel Analog Skalası (VAS) kullanılarak değerlendirildi. Bu skalada $10 \mathrm{~cm}$ 'lik bir çizgide bireyin ağrı şiddetine göre bir nokta seçmesi istendi 0 noktası ağrısız nokta, 10 noktası ise ağrının dayanılmaz olduğu nokta olarak kabul edildi. Bireylerin istirahatteki ağrı şiddetini $10 \mathrm{~cm}$ 'lik çizgi üzerinde işaretlemeleri istendi. Birey tarafından işaretlenen nokta ile 0 noktası arası cetvel ile ölçüldü ve sonuç cm olarak kaydedildi (Downie, Leatham, Rhind ve ark, 1978). Ayrıca omuz bölgesinde ağrı olduğunu belirten hastalara bu ağrının ne kadar süredir sürdüğü soruldu. Hastaların belirtikleri zaman ay olarak kaydedildi.

\section{Engel Seviyesinin Değerlendirilmesi}

Engel seviyesinin değerlendirilmesinde Kol, Omuz ve El Sorunları Anketi (DASH) kullanılarak değerlendirildi. DASH, üst ekstremitenin fonksiyonel durumunu Likert ölçeğine göre subjektif olarak değerlendirir. 3 bölümden oluşmaktadır. Anketten 0 ( hiç engel yok) ile 100 ( şiddetli engel) arası puan alınmaktadır (Duger, Yakut, Oksuz ve ark, 2006).

\section{Hastalık Aktivitesi Değerlendirmesi}

Hastalık aktivitesi Romatoid Artrit Hastalık Aktivitesi İndeksi-5 Türkçe versiyonu (T-RADAl-5) kullanılarak değerlendirildi. RADAI-5 indeksi RADAl indeksinde olan eklem incelemesini içermemektedir. Bu anket özellikle romatolojist olmayan sağlık profesyonelleri için geliştirilmiştir. İndeksin oluşturulmasındaki amaç klinisyenlere zaman kazandırmaktır (Leeb ve ark, 2008; Sunar, Yilmaz Tasdelen, Garip Cimen ve ark, 2014).

\section{Istatistiksel Analiz}

Çalışma verilerinin istatistiksel analizi için Statistical Package for Social Sciences (SPSS) 15 programı kullanıldı. Değişkenlerin normal değılıma uygunluğu görsel (histogram ve olasılık grafikleri) ve ShapiroWilk testleri ile incelendi. Parametrik veriler ortalama \pm standart sapma $(X \pm S S)$ değerleri, parametrik olmayan veriler ortanca (M) ve çeyrekler arası aralık (IQR) ile ifade edildi. Gruplar arası karşılaştırmalarda parametrik veriler için bağımsız gruplar student-t testi, parametrik olmayan veriler için Mann-Whitney $U$ testi kullanıldı. Grup içi karşılaştırmalar Wilcoxon testi ile yapıldı.

\section{SONUÇLAR}

Çalışmaya dâhil edilen 52 hasta skapular diskinezisi olan (Grup 1) ve olmayan (Grup2) şeklinde 26'şar kişilik iki gruba ayrıldı. İki grup arasında yaş, vücut kitle indeksi (VKi), omuz ağrı süresi ve hastalığın durasyonu açısından fark bulunmadı $(p>0,05)$ (Tablo 1).

LSKT sonuçlarına göre merkezden daha uzak olan taraf asimetrik taraf ve karşı taraf ise simetrik taraf olarak isimlendirildi. Grup 1 hastaların 7'sinin sağ tarafı, 19'unun ise sol tarafı asimetrik bulundu. Grup 1 ve 2 hastalarının LSKT sonuçları Tablo 2'de yer almaktadır. Gözlemsel skapular diskinezi 
sonuçlarıan göre 2 hastada biletral 24 hastada ( 6 sağ ve $18 \mathrm{sol}$ ) tarafta skapular diskenezi tespit edildi.

Grupların her iki ekstremite kas kuvveti sonuçları karşılaştırıldığında Grup 2 kas kuvvet sonuçları Grup 1 'nin sonuçlarından yüksek bulundu $(p<0,05)$ (Tablo 3).

Grup 1 hastaların asimetrik taraf ile simetrik taraf omuz çevresi kas kuvvetleri karşılaştırıldığında iki taraf arasında sadece omuz eksternal rotasyon kuvveti açısından simetrik taraf lehine fark bulundu $(p<0,05)$ (Tablo 4).

Grupların DASH-T, T-RADAI-5, RAQoL-T ve VAS sağ ve sol sonuçları Tablo 5'de yer almaktadır. İki grup arasında engel seviyesi, hastalık aktivitesi, yaşam kalitesi ve ağrı değerlendirme sonuçları karşılaştırıldığında Grup 2 lehine fark bulundu $(p<0,05)$.

Tablo 1. Çalışmaya Katılan Hastaların Demografik bilgiler

\begin{tabular}{|c|c|c|c|}
\hline & $\begin{array}{l}\text { Grup } 1 \\
\text { n=26 }\end{array}$ & $\begin{array}{l}\text { Grup } 2 \\
n=26\end{array}$ & $\mathbf{p}$ \\
\hline Yaş (X ISS) (yıl) & $56,35( \pm 8,86)$ & $51,46( \pm 10,02)$ & $p>0,05$ \\
\hline VKI (X $\pm S S)\left(\mathrm{kg} / \mathrm{m}^{2}\right)$ & $31,24( \pm 6,79)$ & $29,94( \pm 5,65)$ & $p>0,05$ \\
\hline Omuz ağrı süresi (ay) [M (IQR)] & $1,5(0-30)$ & $0,38(0-24)$ & $p>0,05$ \\
\hline Hastalığın durasyonu (ay) [M (IQR)] & $114(72-240)$ & $114(60-168)$ & $p>0,05$ \\
\hline
\end{tabular}

M: Ortanca, IQR: Çeyrekler arası aralık, X: Ortalama, SS: Standart sapma, VKI: Vücut Kitle İndeksi

Tablo 2. Çalışmaya Katılan Hastaların Lateral Skapular Kaydırma Test Sonuçları

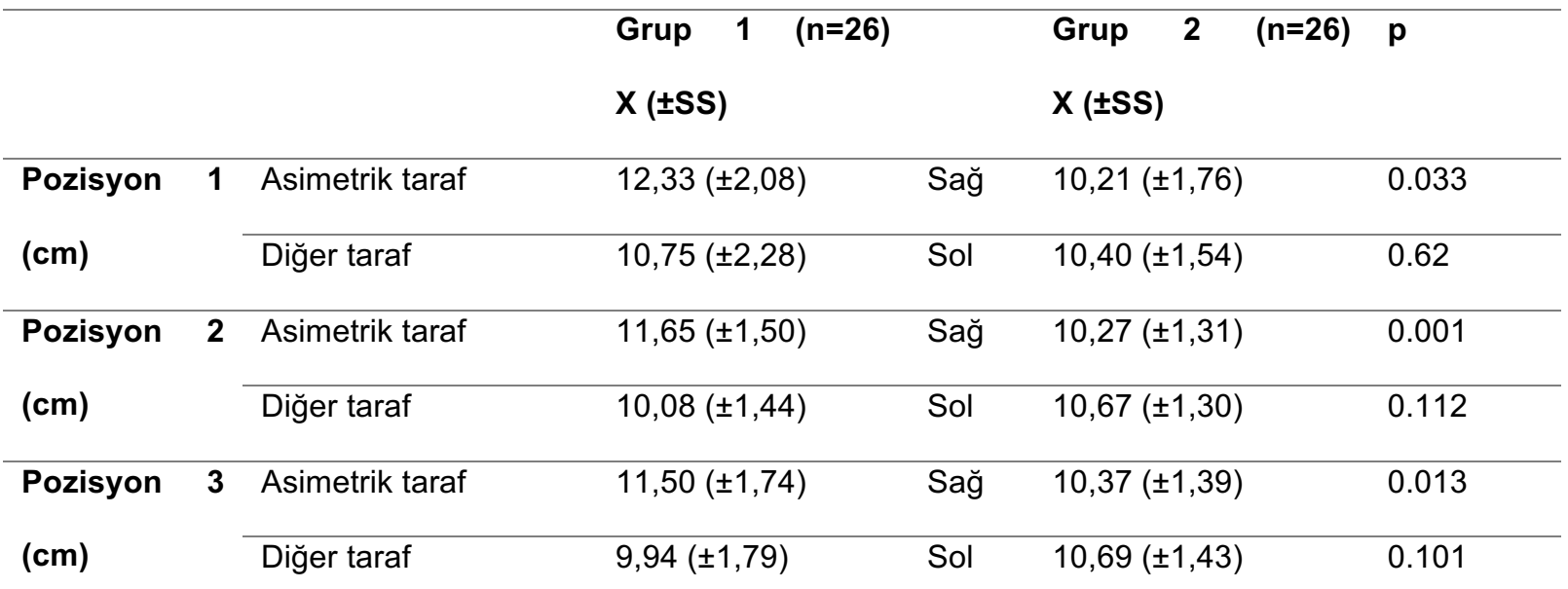

X: Ortalama, SS: Standart sapma, cm: Santimetre. 
Tablo 3. Grupların manuel kas kuvveti ölçüm sonuçları

\begin{tabular}{|c|c|c|c|c|c|c|}
\hline & $\begin{array}{l}\text { Grup } 1 \\
\text { M (IQR) }\end{array}$ & $\begin{array}{l}\text { Grup } 2 \\
\text { M (IQR) }\end{array}$ & $\mathbf{P}$ & $\begin{array}{l}\text { Grup } 1 \\
\text { M (IQR) }\end{array}$ & $\begin{array}{l}\text { Grup } 2 \\
\text { M (IQR) }\end{array}$ & $\mathbf{p}$ \\
\hline & Dominant & Dominant & & $\begin{array}{l}\text { Non- } \\
\text { Dominant }\end{array}$ & $\begin{array}{l}\text { Non- } \\
\text { Dominant }\end{array}$ & \\
\hline Omuz fleksiyon & $3(3-5)$ & $5(4-5)$ & $P<0,001$ & $4(3-4)$ & $5(4-5)$ & $P<0,001$ \\
\hline Omuz abdüksiyon & $3(3-5)$ & $5(4-5)$ & $P=0,001$ & $3(3-4)$ & $5(4-5)$ & $P<0,001$ \\
\hline Supraspinatus & $3(3-5)$ & $5(4-5)$ & $P=0,001$ & $3(3-5)$ & $5(4-5)$ & $P=0,001$ \\
\hline Omuz internal rotasyon & $4(3-5)$ & $5(4-5)$ & $P=0,008$ & $4(3-5)$ & $5(4-5)$ & $P=0,004$ \\
\hline Omuz eksternal rotasyon & $4(3-5)$ & $5(5-5)$ & $P=0,001$ & $4(3-4)$ & $5(5-5)$ & $P<0,001$ \\
\hline Dirsek fleksiyon & $5(4-5)$ & $5(5-5)$ & $P=0,010$ & $4,5(3-5)$ & $5(5-5)$ & $P=0,001$ \\
\hline
\end{tabular}

M: Ortanca, IQR: Çeyrekler arası aralık.

Tablo 4. Grup 1 hastalarının asimetrik ve simetrik taraf omuz çevresi kas kuvvetlerinin karşılaştırılması

\begin{tabular}{|c|c|c|c|}
\hline & $\begin{array}{l}\text { Asimetrik taraf }(n=26) \\
M(I Q R)\end{array}$ & $\begin{array}{l}\text { Simetrik taraf }(n=26) \\
M(I Q R)\end{array}$ & $\mathbf{p}$ \\
\hline Omuz eksternal rotasyon & $4(3-4)$ & $4(3-5)$ & $p=0,046$ \\
\hline Omuz fleksiyon & $3,5(3-4)$ & $4(3-4)$ & $p>0,05$ \\
\hline Omuz abdüksiyon & $3,5(3-4)$ & $3(3-4)$ & $p>0,05$ \\
\hline Supraspinatus & $3,5(3-5)$ & $3,5(3-5)$ & $p>0,05$ \\
\hline Omuz internal rotasyon & $4(3-5)$ & $4(3-5)$ & $p>0,05$ \\
\hline Dirsek fleksiyon & $5(4-5)$ & $5(4-5)$ & $p>0,05$ \\
\hline
\end{tabular}

M: Ortanca, IQR: Çeyrekler arası aralık.

Tablo 5. Çalışmaya Katılan hastaların DASH-T, SPADI-T, T-RADAI-5, RAQoL-T ve VAS değerlerinin karşılaştırılması

\begin{tabular}{|c|c|c|c|}
\hline & Grup $1(n=26)$ & Grup $2(n=26)$ & $\mathbf{p}$ \\
\hline DASH-T [X ( $\pm S S)]$ & $48,58( \pm 15,40)$ & $30,03( \pm 17,76)$ & $p<0,001$ \\
\hline T-RADAI-5 [X ( $\pm S S)]$ & $5,00( \pm 1,60)$ & $2,59( \pm 1,54)$ & $p<0,001$ \\
\hline RAQoL-T [X ( $\pm S S)]$ & $17,35( \pm 5,49)$ & $8,92( \pm 5,52)$ & $p<0,001$ \\
\hline Sağ [M (IQR)] & $4,1 \mathrm{~cm}(0-5,8)$ & $0 \mathrm{~cm}(0-1,3)$ & $p=0,002$ \\
\hline Sol [M (IQR)] & $4,3 \mathrm{~cm}(0-6,6)$ & $0 \mathrm{~cm}(0-1,5)$ & $p=0,001$ \\
\hline
\end{tabular}

M: Ortanca, IQR: Çeyrekler arası aralık, X: Ortalama, SS: Standart sapma, DASH-T: Kol, Omuz ve El Sorunları Anketi Türkçe versiyonu, T-RADAI-5: Romatoid Artrit Yaşam Kalitesi Anketi Türkçe versiyonu, RAQoL-T: Romatoid Artrit Hastalık Aktivite İndeksi-5 Türkçe versiyonu, VAS: Görsel Analog Skalası 


\section{TARTIŞMA}

Çalışmamız RA'lı hastalarda skapular diskinezinin yaşam kalitesi ve engel seviyesi üzerine etkisini araştırmak için yapıldı. Bu çalışma sonucunda skapular diskinezinin engel seviyesi, ağrı düzeyi ve yaşam kalitesi üzerine olumsuz etkisi olduğu belirlendi. Skapular diskinezisi olan RA'lı hastalar, skapular diskinezisi olmayanlara kıyasla yaşam kalitesi, kas kuvveti sonuçlarının daha düşük olduğu, hastalık aktivitesi, ağrı ve engel seviyesinin ise daha yüksek olduğu belirlendi. Diskinezili olguların simetrik ve asimetrik taraf omuz çevresi kas kuvveti açısından ise asimetrik tarafta sadece eksternal rotasyon kas kuvvetinin daha düşük olduğu bulundu.

Skapular hareketlerdeki değişiklikler sıklıkla omuz ile ilgili yaralanma ve disfonksiyonlarla ilgilidir (Varnell 2015; Ludewig ve Reynolds, 2009; Kibler ve McMullen, 2003). Skapular diskinezinin neden olduğu ya da skapular diskineziye neden olduğu düşünülen bu patolojiler arasında sıkışma sendromu, rotator kas yırtıkları, labral yırtıklar, klavikula kırıkları, akromiyoklavikular eklem patolojileri, nörolojik problemler, tendinopatiler ve çok yönlü instabiliteler yer alır (Kibler ve ark, 2003; Odom, Taylor, Hurd ve ark, 2001; López-Vidriero, López-Vidriero, Rosa ve ark, 2015). Yaklaşık olarak RA'lı hastaların \%70-90'। omuz problemi yaşamaktadır (Clarke, Willis, Fish ve ark, 1975). RA'ı hastaların şikâyet ettiği omuz ağrısının rotatör manşet yırtıkları ile ilişkili olabileceği belirtilmiştir (Boström, Harms-Ringdahl ve Nordemar 1991; Smith, Sperling ve Cofield, 2005). RA'da rotatör manşet omuz eklem kapsülündeki inflamasyon sürecinden doğrudan etkilenebilir. Ancak rotatör manşetteki kassal zayıflamanın, ağrının kas kontraksiyonunu engelleyen doğal sürecinden kaynaklanan bir sonuç olması da muhtemeldir (Boström ve ark. 1995). Omuz elevasyonu hem glenohumeral hem de skapular hareketi içerir ve skapular kaslar ve rotatör manşetin birlikte sağladığı aktif kontrolü gerektirmektedir. Bu nedenle kolun elevasyonundaki aktif hareket ve aktif kontrol mekanizmasındaki bozulmalar rotatör manşet kasındaki disfonksiyonlarla açıklanmaya çalışılmaktadır (Magarey ve Jones, 2003). RA'lı omuzda inflamatuvar süreç ile birlikte gelişen ve kas yırtıklarına kadar ilerleyen yumuşak doku patolojileri yapılan çalışmalarla aşikârdır. Literatürde RA'da skapular diskineziyi gösteren bir çalışmaya rastlanmamıştır. Yukarıda belirttiğimiz patolojilerin sonucu gelişen biyomekaniksel dengesizliklerin
RA'da skapular diskineziye zemin hazırlayabileceğini düşünmekteyiz.

Neden ya da sonuç olarak skapular diskinezi ile ilişkili patolojilerde, hemen hemen en önemli semptomlardan birisi ağrıdır (Struyf, Nijs, Mollekens ve ark, 2013; De Mey, Danneels, Cagnie ve ark, 2012; Scibek, Mell, Downie ve ark, 2008; Yüksel, 2014; Kibler ve Sciascia, 2010; Kelly, Foster ve Fisher, 1987). Omuzda ağrı, fonksiyon kaybıyla birlikte anatomik, fizyolojik ve biyomekanik değişikliklerin gelişmesine zemin hazırlar. Bu nedenle oluşan patomekanik durumlar kinetik zincirin değişmesine, hâlihazırdaki yaralanma şiddetinin artmasına ya da yeni yaralanmalar için risk oluşmasına neden olur (Elliott, Fleisig, Nicholls ve ark, 2003; Wilk, Macrina, Fleisig, 2011).

RA'lı hastaların da başlıca şikâyetlerinden birisi ağrıdır (Heigberg ve Kvien 2002). Yapılan çalışmalarda RA'lı hastaların yaklaşık \%70'inin en büyük isteğinin ağrılarının azalması olduğunu ifade edilmiştir (Heigberg ve ark, 2002; Selby, 2011; Buckelew ve Parker, 1989). İnflamatuvar sürecin hâkim olduğu RA'da diğer eklemlerde olduğu gibi omuzda da ağrı mekanizmasının oluşması kaçınılmazdır. Yapılan bir çalışmada günlük aktivitelerde omuz ağrısının fonksiyonları olumsuz etkilediği ve ağrının aktivitelerdeki oluşan limitasyonlardan en fazla sorumlu olan etmenlerden biri olduğu belirtilmiştir (Vermeulen, Breedveld, Le Cessie ve ark, 2006). Ağrı ve skapular diskinezinin birlikte klinik semptom oluşturması literatürle paralel olarak bizim sonuçlarımıza da yansıdı. Beklendiği gibi diskinezi semptomu olan olgulardaki ağrı, olmayanlara oranla fazlaydı. Fakat unileteral skapular diskinezili hastalar ağırlıkta olmasına rağmen uniletral skapular diskinezisinin görüldüğü sıkışma sendromunun aksine hastalarımızın iki omuz ağrısı karşılaştırıldığında, ne skapular diskinezisi olan grup ne de skapular diskinezisi olmayan grupta oluşan fark anlamlı düzeyde değildir. Litertürde yaşanan kronik ağrının ağrı hafızası oluşturarak ağrı çağrışımı yaptırabileceği belirtilmektedir (Lefebvre ve Keefe, 2002; Melzack, Ronald, ve Scott, 1957). RA'lı hastaların kronik bilateral yaşadıkları ağrıdan kaynaklı oluşacabilecek ağrı hafızalarının, karşı omuzlarında ağrı oluşmasına neden olabilecek bir etken olmasa bile hastaların ağrı hissetmesine neden olabileceğini düşünmekteyiz. RA'da ağrı, diğer romatolojik hastalıklarda da olduğu gibi en belirgin klinik semptomdur. Ağrı ve inflamasyona bağlı gelişen 
şişlik diğer mekanik bulguların yanı sıra, RA'da hastalık aktivitesini gösteren öncelikli klinik bulgular olduğu unutulmamalıdır (Liao ve Karlson, 2015). Çalışmamızda iki grup hastalık aktivitesi açısından da farklılık gösterdi. Diskinezisi olan olguların hastalık aktiviteleri yüksekti. Bu nedenle hastaların ağrı seviyeleri arasındaki farkın oluşmasına hastalık aktivitesinin daha çok katkı sağlayabileceğini düşünmekteyiz.

Ağrının kas inhibisyonuna ve kas kuvvetinde azalmaya neden olduğu bilinmektedir (Spencer, Hayes ve Alexander, 1984). Omuz ağrısının, omuz çevresi kas kuvvetini etkilemesi beklenen bir durumdur (Porter ve Brittain, 2012; Spencer, Hayes ve Alexander, 1982; Erol, Özçakar ve Çeliker, 2008; MacDermid, Ramos, Drosdowech ve ark, 2003). RA'lı hastaların kas kuvveti sağlıklı yaşıtlarına göre daha zayıftır ve ağrının azalmasıyla kuvvetin ve kavrama fonksiyonunun geliştiğini belirtilmiştir (Porter ve ark, 2012; Ekdahl ve Broman, 1992; Nordenskiöld, 1990; Ekblom, Lovgren, Alderin ve ark, 1974; Ahlmén, Nordenskiöld, Archenholtz ve ark, 2005). Literatürde omuz patolojileri olan hastalarda kuvvet azlığı ve ağrıya yönelik tedavilerin kuvvet ve fonksiyona katkısı gösterilmiştir (Ballantyne, O'Hare, Paschall, 1993; Ben-Yishay, Zuckerman, Gallagher ve ark, 1994). Çalışmamızda skapular diskinezi varlığına göre sınıflandırdığımız olgular arasında omuz çevresi kas kuvvetinde fark elde ettik. Yukarıdaki literatür özeti ışığında, ağrı seviyesi yüksek olan diskinezili olguların hem ağrı seviyelerinin fazlalığı hem de skapular pozisyondaki değişimle gelişen omuz çevresi kasların uzunluk gerilim ilişkisindeki bozulmanın kas kuvvetinde azalmaya neden olabileceğini düşünmekteyiz.

Çalışmamızda elde ettiğimiz sonuçlara göre diskinetik olguların yaşam kalitesi ve fonksiyonellik seviyelerinin düşük olduğu belirlendi. Literatürü incelediğimizde diskinezi ile ilgili patolojilerde fonksiyonellik ve yaşam kalitesi azalmaktadır (MacDermid ve ark, 2004; Viikari-Juntura, Shiri, Solovieva ve ark, 2008; Walker-Bone, Palmer, Reading ve ark, 2004; Luime, Koes, Hendriksen ve ark, 2004; Chipchase, O'Connor, Costi ve ark, 2000; Bjelle, 1989; Ostor, Richards, Prevost ve ark, 2005; Van der Windt, Koes, De Jong ve ark, 1995). Oysa bizim olgularımızda bu patolojilerin varlığı ile ilgili bir veri yoktu. Olgularımızdaki en net veri ağrıları ve hastalık aktiviteleridir. RA'da ağrı ve hastalık aktivitesi ile yaşam kalitesi ve fonksiyonellik ile ilişkiyi net koyan çalışmalar mevcuttur (Porter ve ark, 2012; Welsing, Van Gestel, Swinkels, 2001; Merolla, De Santis, Sperling ve ark, 2010; Guillemin, Briancon ve
Pourel, 1992). Bu nedenle diskinetik ve diskinetik olmayan olgular arasındaki farkın ağrı ve hastalık aktivitesi seviyeleri ile ilişkili olabileceğini düşünüyoruz.

$\mathrm{Bu}$ çalışmayı gerçekleştirirken bazı limitasyonlarla karşılaşıldı. Skapular diskineziyi değerlendirmek için gözlemsel metod ve LSKT yerine üç boyutlu skapular hareket analiz yöntemi kullanılsaydı skapular kinematik ile ilgili detaylı ve nicel bilgi elde edilebilirdi. Ayrıca hastaların omuz fonksiyonu sırasındaki ağrıları ve ağrı hafızası değerlendirilseydi ağrı ile ilgili sonuçlar daha net tartışılabilirdi. Bu iki durumun çalışmamızın başlıca limitasyonları olduğunu düşünüyoruz. Çalışmamızda hastaların üst ekstremite dışındaki eklemleri ve eklem dışı tutulumları ayrıntılı araştırılmadığı ve genel yaşam kalitesi değelendirildiği için iki grup arasındaki yaşam kalitesindeki farka skapular diskinezi etkisi tam olarak net incelenememiştir. Ancak yaşam kalitesindeki bu farkın önemli olduğunu düşünmekteyiz. Bu nedenle yaşam kalitesindeki farkın nendenlerini araştıran ileri araştırmalara intiyaç vardır.

$\mathrm{Bu}$ çalışmanın sonucuna göre RA'lı hastalarda inflamatuar süreç, diğer tüm eklemlerde de olduğu gibi skapulatorasik eklem ve çevresindeki yapıları da etkiler. Oluşan biyomekaniksel dengesizlikler bu hastalarda skapular dizkineziye neden olabilir. Skapular diskinezi bu hastaların yaşam kalitesi ve engel seviyesi ile ilişkilidir. Bu nedenle RA ile ilgili omuz patolojilerinde uygulanacak tedavi programlarının başarısını arttırmak için klinik değerlendirmelere, skapulanın kinematiği de dâhil edilmelidir.

\section{Teşekkür}

Çalışmaya dâhil edilen hastaların RA tanılarını koyan ve çalışmamıza katkı sağlayan Doç. Dr. Abdurrahman Tufan'a teşekkür ederiz.

\section{Kaynaklar}

Ahlmén, M., Nordenskiöld, U., Archenholtz, B., Thyberg, I., Rönnqvist, R., Lindén, L., Andersson, A. K., \& Mannerkorpi, K. (2005). Rheumatology outcomes: the patient's perspective. A multicentre focus group interview study of Swedish rheumatoid arthritis patients. Rheumatology (Oxford), 44(1), 105-110.

Ballantyne, B.T., O'Hare, S.J., Paschall, J. L., Pavia-Smith, M. M., Pitz, A. M., Gillon, J. F., \& Soderberg., G. L. (1993). Electromyographic activity of selected shoulder muscles in commonly used therapeutic exercises. Phys Ther, 73(10), 668-677. 
Ben-Yishay, A., Zuckerman, J. D., Gallagher, M., \& Cuomo, F. (1994). Pain inhibition of shoulder strength in patients with impingement syndrome. Orthopedics, 17(8), 685-688.

Bilberg, A., Bremell, T., \& Mannerkorpi, K. (2012). Disability of the Arm, Shoulder and Hand questionnaire in Swedish patients with rheumatoid arthritis: A validity study. J Rehabil Med, 44(1), 7-11.

Bjelle, A. (1989). Epidemiology of shoulder problems. Baillieres Clin Rheumatol, 3(3), 437-51.

Boström, C., Harms-Ringdahl, K., \& Nordemar, R. (1991). Clinical reliability of shoulder function assessment in patients with rheumatoid arthritis. Scand J Rehabil Med, 20(1), 36-48.

Boström, C., Harms-Ringdahl, K., \& Nordemar, R. (1995). Relationships between measurements of impairment, disability, pain, and disease activity in rheumatoid arthritis patients with shoulder problems. Scand J Rehabil Med, 24(6), 352-359.

Böstrom C. (2000). Shoulder rotational strength, movement, pain and joint tenderness as indicators of upper-extremity activity limitation in moderate rheumatoid arthritis. Scand J Rehabil Med, 32(3), 134-9.

Buckelew, S. P., \& Parker, J. C. (1989). Coping with arthritis pain: A review of the literature. Arthritis Care Res, 2(4), 136-145.

Burkhart, S. S., Morgan, C. D., \& Kibler, W. B. (2000). Shoulder injuries in overhead athletes. The "dead arm" revisited. Clin Sports Med, 19(1), 125-58.

Chipchase, L. S., O'Connor, D. A., Costi, J. J., \& Krishnan, J. (2000). Shoulder impingement syndrome: preoperative health status. J Shoulder Elbow Surg, 9(1), 12-5.

Clarke G. R., Willis L. A., Fish W. W., \& Nichols P. J. (1975). Preliminary studies in measuring range of motion in normal and painful stiff shoulders. Rheumatol Rehabil, 14(1), 39-46.

De Mey, K., Danneels, L., Cagnie, B.,\& Cools, A. M. (2012). Scapular muscle rehabilitation exercises in overhead athletes with impingement symptoms effect of a 6-week training program on muscle recruitment and functional outcome. Am J Sports Med, 40(8), 1906-1915.

Downie, W.W., Leatham, P. A., Rhind, V. W., Wright, V., Branco, J. A., \& Anderson, J. A. (1978). Studies with pain rating scales. Ann Rheum Dis, 37(4), 378-381.

Duger, T., Yakut, E., Oksuz, C., Yorukan, S., Bilgutay, B. S., Ayhan, Ç., Leblebicioğlu, G., Kayıhan, H., Kırdı, N., Yakut, Y., \& Güler, Ç. (2006). Reliability and validity of the Turkish version of the Disabilities of the Arm, Shoulder and Hand (DASH) Questionnaire. Fizyoterapi Rehabilitasyon, 17(3), 99-107.

Ekblom, B., Lovgren, O., Alderin, M., Fridstrom, M., \& Satterstrom, G. (1974). Physical performance in patients with rheumatoid arthritis. Scand J Rheumatol, 3(3), 1215.

Ekdahl, C., \& Broman, G. (1992). Muscle strength, endurance, and aerobic capacity in rheumatoid arthritis: a comparative study with healthy subjects. Ann Rheum Dis, 51(1), 35-40.

Elliott, B., Fleisig, G., Nicholls, R., \& Escamilia, R. (2003). Technique effects on upper limb loading in the tennis serve. J Sci Med Sport, 6(1), 76-87.

Erol, Ö., Özçakar, L., \& Çeliker, R. (2008). Shoulder rotator strength in patients with stage I-II subacromial impingement: Relationship to pain, disability, and quality of life. J Shoulder Elbow Surg, 17(6), 893-7.

Guillemin, F., Briancon, S.,\& Pourel, J. (1992). Functional disability in rheumatoid arthritis: two different models in early and established disease. J Rheumatol, 19(3), 3669.

Heigberg, T., \& Kvien, T. K.(2002). Preferences for improved health examined in 1024 patients with rheumatoid arthritis: pain has the highest priority. Arthritis Rheum , 47(4), 391-397.

Helmick, C. G., Felson, D. T., Lawrence, R. C., Gabriel, S., Hirsh R., \& Kwoh, K. (2008). National Arthritis Data Workgroup. Estimates of the prevalence of arthritis and other rheumatic conditions in the United States. Arthritis Rheum, 58(1), 15-25.

Kelly, I. G., Foster, R. S., \& Fisher, W. D. (1987). Neer total shoulder replacement in rheumatoid arthritis. J Bone Joint Surg $\mathrm{Br}, 69(5)$, 723-726.

Kibler, W. B.(1998). The role of the scapula in athletic shoulder function. Am J Sports Med, 26(2), 325-337.

Kibler, B. W., \& McMullen, J. (2003). Scapular dyskinesis and its relation to shoulder pain. J Am Acad Orthop Surg, 11(2), 142-151.

Kibler, W.B., \& Sciascia, A. (2010). Current concepts: scapular dyskinesis. Br J Sports Med, 44(5), 300-305.

Kibler, W.B., Ludewig, P.M., McClure, P.W., Michener, L.A., Bak, K., \& Sciascia, A.D. (2013). Clinical implications of scapular dyskinesis in shoulder injury: the 2013 consensus statement from the 'Scapular Summit'. Br J Sports Med, 47(14), 877-85.

Krabben, A., Huizinga, T.W.,\& van der Helm-van Mil, A.H. (2012). Undifferentiated arthritis characteristics and outcomes when applying the 2010 and 1987 criteria for rheumatoid arthritis. Ann Rheum Dis, 71(2), 238-41.

Kutlay, S., Küçükdeveci, A. A., Gönül, D., \& Tennant, A. (2003). Adaptation and validation of the Turkish version of the Rheumatoid Arthritis Quality of Life Scale. Rheumatol Int, 23(1), 21-26.

Leeb, B. F., Haindl, P. M., Maktari, A., Nothnagl, T., \& Rintelen, B. (2008). Patient-centered rheumatoid arthritis disease activity assessment by a modified RADAI. J Rheumatol, $35,1294-9$.

Lefebvre, J. C., \& Keefe, F. J. (2002). Memory for pain: the relationship of pain catastrophizing to the recall of daily rheumatoid arthritis pain. Clin J Pain, 18(1), 56-63.

Liao, K.P., \& Karlson, E.W. (2015). Classification and epidemiology of rheumatoid arthritis. In M.C. Hochberg, A.J. Silman, J.S. Smolen, M.E. Weinblatt, \& M.H. Weisman (Eds.), Rheumatology (6th Edition, pp. 691697). Philadelphia: Mosby Elsevier.

López-Vidriero, E., López-Vidriero, R., Rosa, L. F., Gallardo, E., Fernández, J. A., Arriaza, R., \& Ballesteros, J. (2015). Scapular Dyskinesis: Related Pathology. International Journal of Orthopaedics, 2(1), 191-195.

Ludewig, P. M., \& Reynolds, J. F. (2009). The association of scapular kinematics and glenohumeral joint pathologies. J Orthop Sports Phys Ther, 39(2), 90-104.

Luime, J.J., Koes, B.W., Hendriksen, I.J., Burdorf, A., Verhagen, A.P., Miedema, H.S., \& Verhaar, J. A. (2004). Prevalence and incidence of shoulder pain in the general population: a systematic review. Scand J Rheumatol, 33(2), 73-81

MacDermid, J.C., Ramos, J., Drosdowech, D., Faber, K., \& Patterson, S. (2004). The impact of rotator cuff pathology 
on isometric and isokinetic strength, function, and quality of life. J Shoulder Elbow Surg, 13(6), 593-8.

Magarey, M. E., \& Jones, M. A. (2003). Dynamic evaluation and early management of altered motor control around the shoulder complex. Man Ther, 8(4), 195-206.

McKay, A. (2015). Scapular dyskinesis and its correlation to history of shoulder injuries and supraspinatus strength in NCAA division III baseball players( Master Thesis). The College of St. Scholastica, Ann Arbor, 23-29.

Melzack, R., \& Scott, T. H. (1957). The effects of early experience on the response to pain. J Comp Physiol Psychol, 50(2), 155.

Merolla, G., De Santis, E., Sperling, J. W., Campi, F., Paladini, P., \& Porcellini, G. (2010). Infraspinatus strength assessment before and after scapular muscles rehabilitation in professional volleyball players with scapular dyskinesis. J Shoulder Elbow Surg, 19(8), 12561264.

Nordenskiöld, U. (1990). Elastic wrist orthoses. Reduction of pain and increase in grip force for women with rheumatoid arthritis. Arthritis Care Res, 3(3), 158-62.

O'Dell J. R., Imboden, J. B., \& Miller, L. D. (2013). Rheumatoid arthritis \& Spondyloarthropathies. J.B. Imboden, D.B. Hellmann,\& J.H. Stone (Eds.), Current Diagnosis \& Treatmet (Third edition, pp. 139-155). New York: The McGraw-Hill Education.

Odom, C. J., Taylor, A. B., Hurd, C. E., \& Denegar, C. R. (2001). Measurement of scapular asymmetry and assessment of shoulder dysfunction using the Lateral Scapular Slide Test: a reliability and validity study. Phys Ther, 81(2), $799-809$.

Ostor, A. J., Richards, C. A., Prevost A.T., Speed C.A., \& Hazlemen B. L. (2005). Diagnosis and relation to general health of shoulder disorders presenting to primary care. Rheumatology, 44(6), 800-5.

Paletta, G. A., Warner, J. J., Warren, R. F., Deutsch, A., \& Altchek, D.W. (1997). Shoulder kinematics with two-plane $x$-ray evaluation in patients with anterior instability or rotator cuff tearing. J Shoulder Elbow Surg, 6(6), 516-27.

Porter, B. J., \& Brittain, A. (2012). Splinting and hand exercise for three common hand deformities in rheumatoid arthritis: a clinical perspective. Curr Opin Rheumatol, 24(2), 215221.

Scibek, J. S., Mell, A. G., Downie, B. K., Carpenter, J. E., \& Hughes, R.E. (2008). Shoulder kinematics in patients with full-thickness rotator cuff tears after a subacromial injection. J Shoulder Elbow Surg,17(1), 172-181.

Selby, M. (2011). Managing chronic pain. Practice Nurse, 41(2), 14-19.

Slungaard, B., \& Mengshoel, A. M. (2013). Shoulder function and active motion deficit in patients with rheumatoid arthritis. Disabil Rehabil, 35(16), 1357-63.

Smith, A. M., Sperling, J. W., \& Cofield, R. H. (2005). Rotator cuff repair in patients with rheumatoid arthritis. J Bone Joint Surg Am, 87(8), 1782-1787.

Spencer, J. D., Hayes, K. C., \& Alexander, I. J. (1984). Knee joint effusion and quadriceps reflex inhibition in man. Arch Phys Med Rehabil, 65(4), 171-177.

Stegbauer, J., Rump, L. C. \& Weiner, S. M. (2008). Sites of inflammation in painful rheumatoid shoulder assessed by musculoskeletal ultrasound and power Doppler sonography. Rheumatol Int, 28, 459-465.

Struyf, F., Nijs, J., Mollekens, S., Jeurissen, I., Truijen, S.,
Mottram, S., \& Meeusen, R. (2013). Scapular-focused treatment in patients with shoulder impingement syndrome: a randomized clinical trial. Clin Rheumatol, 32(1), 73-85

Sunar, I., Yilmaz Tasdelen, O., Garip Cimen, Y., \& Bodur, H. (2014). Translation and validation of the Turkish language version of the Rheumatoid Arthritis Disease Activity Index5. Int J Rheum Dis, 12, 1-8.

Tamowska C., Amernik K., Matyia G., Brzsko I., Grzelec H., \& Burak M. (2004). Fixation of the crico-arytenoid joints in rheumatoid arthritis-preliminary report. Otolaryngol Pol, 58(4), 843-9.

Uhl, T.L., Kibler, W.B., Gecewich, B.,\& Tripp, B.L. (2009). Evaluation of clinical assessment methods for scapular dyskinesis. Arthroscopy, 25(11), 1240-1248.

Urwin, M., Symmons, D., Allison, T., Brammah, T., Busby, H., Roxby, M., Simmons, A., \& Williams, G. (1998). Estimating the burden of musculoskeletal disorders in the community: the comparative prevalence of symptoms at different anatomical sites, and the relation to social deprivation. Ann Rheum Dis, 57(11), 649-55.

Van der Windt, D.A., Koes, B.W., De Jong, B.A., \& Bouter LM. (1995). Shoulder disorders in general practice: incidence, patient characteristics, and management. Ann Rheum Dis, 54(12), 959-64.

Varnell, M.S. (2015). The evaluation of scapular kinematics and muscular characteristics of the scapular stabilizers in overhead athletes presenting with scapular dyskinesis compared to healthy controls (Doctoral Thesis). University of Pittsburgh School of Health and Rehabilitation Sciences, Pittsburg, 4-40.

Vermeulen, H. M., Breedveld, F. C., Le Cessie, S., Rozing, P. M., van den Ende, C. H. M., \& Vlieland, T.V. (2006). Responsiveness of the shoulder function assessment scale in patients with rheumatoid arthritis. Ann Rheum Dis, 65(2), 239-241.

Viikari-Juntura, E., Shiri, R., Solovieva, S., Karpinnen, J., Leino-Arjas, P., Varonen, H., Kalso, E., \& Ukkola, O. (2008). Risk factors of atherosclerosis and shoulder pain - Is there an association?. A systemic Review. Eur J Pain, 12(4), 412-426.

Walker-Bone, K., Palmer, K.T., Reading, I., Coggon, D., \& Cooper, C. (2004). Prevalence and impact ofmusculoskeletal disorders of the upper limb in the general population. Arthritis Rheum, 51(4), 642-651.

Warner, J.J., Micheli, L.J., Arslanian, L.E., Kennedy, J.,\& Kennedy, R.(1992). Scapulothoracic motion in normal shoulders and shoulders with glenohumeral instability and impingement syndrome. A study using Moire topographic analysis. Clin Orthop Relat Res. 285, 191-9.

Warth, R. J.,\& Millett, P. J. (2015). Physical examination of the shoulder: An Evidence-Based Approach, (pp. 219-239). New York: Springer.

Welsing, P. M., Van Gestel, A. M., Swinkels, H. L., Kiemeney, L.A., \& Van Riel, P. L. (2001). The relationship between disease activity, joint destruction, and functional capacity over the course of rheumatoid arthritis. Arthritis Rheum, 44(9), 2009-17.

Wilk, K. E., Macrina, L. C., Fleisig, G. S., Porterfield, R., Simpson, C. D., Harker, P., Paparesta, N., \& Andrews, J. R. (2011). Loss of internal rotation and the correlation to shoulder injuries in professional baseball pitchers. Am J Sports Med, 39(2), 329-335. 
Yüksel, E. (2014). Skapular diskinezisi olan subakromial sıkışma sendromlu olgularda skapular stabilizasyon egzersizlerinin etkinliği (Yüksek Lisans Tezi). Dokuz Eylül Üniversitesi Sağlık Bilimleri Enstitüsü, İzmir, 5-8. 